\title{
Reduction of Hepatotoxicity Induced by Acetaminophen Overdoses in a Mouse Model of Inflammation Induced by Freund's Adjuvants
}

Noel Pérez García ${ }^{1}$, Onel Fong Lores², Deivys Portuondo Fuentes ${ }^{3}$, Damiana Téllez Martínez ${ }^{4}$, Juan Betancourt Hernandez², Lidia Páez Rivas $^{1}$, Oliver Pérez Martin ${ }^{5}$ and Alexander Batista-Duharte ${ }^{2,3 *}$

${ }^{1}$ University of Havana, Faculty of Biochemistry, Havana City, Cuba

${ }^{2}$ Toxicology and Biomedicine Center (TOXIMED), Medical Sciences University, Santiago de Cuba, Cuba

${ }^{3}$ Universidade Estadual Paulista, Faculdade de Ciências Farmacêuticas Departamento de Análises Clínicas, Araraquara, SP, Brazil

${ }^{4}$ Faculty of Chemical Enginery, Oriente Universitym, Ave Las Americas, Santiago de Cuba, Cuba

${ }^{5}$ University of Medical Science, Department of Immunology, Havana, Cuba

\begin{abstract}
Acetaminophen (APAP) is often used as an analgesic and antipyretic during the inflammatory process Its toxicity in overdoses depends on the integrity of the hepatic cytochrome P450 (CYP). The oxidative drug metabolism mediated by CYP can be inhibited during inflammatory diseases or after use of immuno-stimulants drugs and vaccines. The objective of this work was to evaluate if inflammation is able to modulate the toxicity of APAP. Five female Balb/c mice were injected subcutaneously with Freund Complete Adjuvant (FCA), and boosted with Freund's Incomplete Adjuvant (FIA) at $14^{\text {th }}$ day. Then, they were treated with $360 \mathrm{mg} / \mathrm{kg}$ of acetaminophen orally during the $14^{\text {th }}, 15^{\text {th }}$ and $16^{\text {th }}$ days. Convenient control groups were included with APAP administration without immuno-stimulation. Serum levels of IL-1 $\beta$, TNFa, IFN $\gamma, \alpha-1$-acid glycoprotein ( $\alpha-1$-AGP), alanine transaminase (ALT), aspartic acid aminotransferase (AST), lactate dehydrogenase (LDH) and hepatic CYP2E1 expression were measured. Inoculation site of adjuvants and liver histopathological responses were also evaluated. FCA/FIA injection produced acute inflammatory response in the inoculation site and increased serum levels of the pro-inflammatory cytokines, $\alpha-1-A G P$ and LDH with reduction of hepatic CYP2E1 expression. A reduction of liver damage induced by APAP overdoses was also observed, suggesting that inflammatory processes can be protective against APAP hepatotoxicity.
\end{abstract}

Keywords: Inflammation; Immunotoxicity; Freund's adjuvants; Acetaminophen; Hepatotoxicity

\section{Introduction}

It has been documented that when host defense mechanisms are stimulated, there is a concomitant decrease in different hepatic cytochrome P450 enzymes (CYP), with impact in the drug biotransformation and elimination. This has resulted in a number of clinically important unwanted drug responses in patients with infections or inflammatory responses [1]. Moreover, several reports has shown that the administration of immuno-stimulating drugs, such as influenza and Bacillus Calmette Guerin (BCG) vaccinations, endotoxins or interferons, can affect the metabolism of several drugs [2-4]. Analgesics and antipyrectics are often co-administered with immuno-stimulatory drugs, after vaccine application or during disease states with an inflammatory component; consequently, the study of these interactions is very important for the prediction of toxicity manifestation in treated patients.

Acetaminophen ( $N$-acetyl-p-aminophenol) (APAP), also referred to as paracetamol, is one of the common analgesics and antipyretic drugs. It is generally considered harmless at therapeutic doses, but in overdose causes severe and sometimes fatal hepatic damage in humans and experimental animals $[5,6]$. The main metabolic pathways of acetaminophen in humans are hepatic glucuronidation and sulphation. Furthermore, several CYP isoenzymes metabolize a small proportion of APAP at therapeutic doses being oxidized to N-acetyl-pbenzoquininemine (NAPQI), a highly reactive intermediate metabolite that yields hepatotoxicity. In overdoses the production of NAPQI increases producing severe hepatic damage [6] (Figure 1).

Pharmacokinetics studies in human volunteers and animal models have evidenced that CYP2E1 is the main CYP isoform involved in the hepatotoxiciy of APAP, although other isoforms such as: CYP1A2,
CYP3A4 and CYP2A6 may also participate [7-9]. The importance of CYP2E1 in acetaminophen toxicity was demonstrated by the finding that CYP2E1 null mice were much less sensitive to acetaminophen hepatotoxicity than the wild-type mice or CYP1A2 null mice. The double null mice (CYP2E1-/-; CYP1A2-/-) were only mildly sensitive to the toxic effects of acetaminophen. Moreover, in CYP2E1 null mice in which the human CYP2E1 gene was introduced as an artificial chromosome genomic clone of bacterial origin, the hepatotoxic effects of acetaminophen were restored to a significant extent $[10,11]$.

Oxidative stress is also considered to be involved in the induction of hepatotoxicity by APAP overdose, causing decreasing in antioxidant enzyme activities such as catalase and glutathione peroxidase, increasing the effect of reactive oxygen species (ROS) like hydrogen peroxide, superoxide and peroxynitrite [12-15].

Various authors reported a rapid decrease in total CYP contents in FCA-induced inflammation in rat liver and the selective downregulation of specific CYP isoforms, as illustrated by decreased mRNA

*Corresponding author: Alexander Batista Duharte, Immunotoxicology Laboratory, Toxicology and Biomedicine Center (TOXIMED), Medical Sciences University, P.O. Box 4033 National Highway, Km 1 1/2. Santiago de Cuba Cuba, Tel: 532264 3796, 5322643926; Fax: 5322643864, 5322687188; E-mail: batistaduhartea@gmail.com

Received June 05, 2014; Accepted July 11, 2014; Published July 18, 2014

Citation: García NP, Lores OF, Fuentes DP, Martínez DT, Hernandez JB, et al (2014) Reduction of Hepatotoxicity Induced by Acetaminophen Overdoses in Mouse Model of Inflammation Induced by Freund's Adjuvants. J Allergy Ther 5 : 183. doi:10.4172/2155-6121.1000183

Copyright: ( 2014 García NP, et al. This is an open-access article distributed under the terms of the Creative Commons Attribution License, which permits unrestricted use, distribution, and reproduction in any medium, provided the original author and source are credited. 
Citation: García NP, Lores OF, Fuentes DP, Martínez DT, Hernandez JB, et al. (2014) Reduction of Hepatotoxicity Induced by Acetaminophen Overdoses in a Mouse Model of Inflammation Induced by Freund's Adjuvants. J Allergy Ther 5: 183. doi:10.4172/2155-6121.1000183

Page 2 of 7

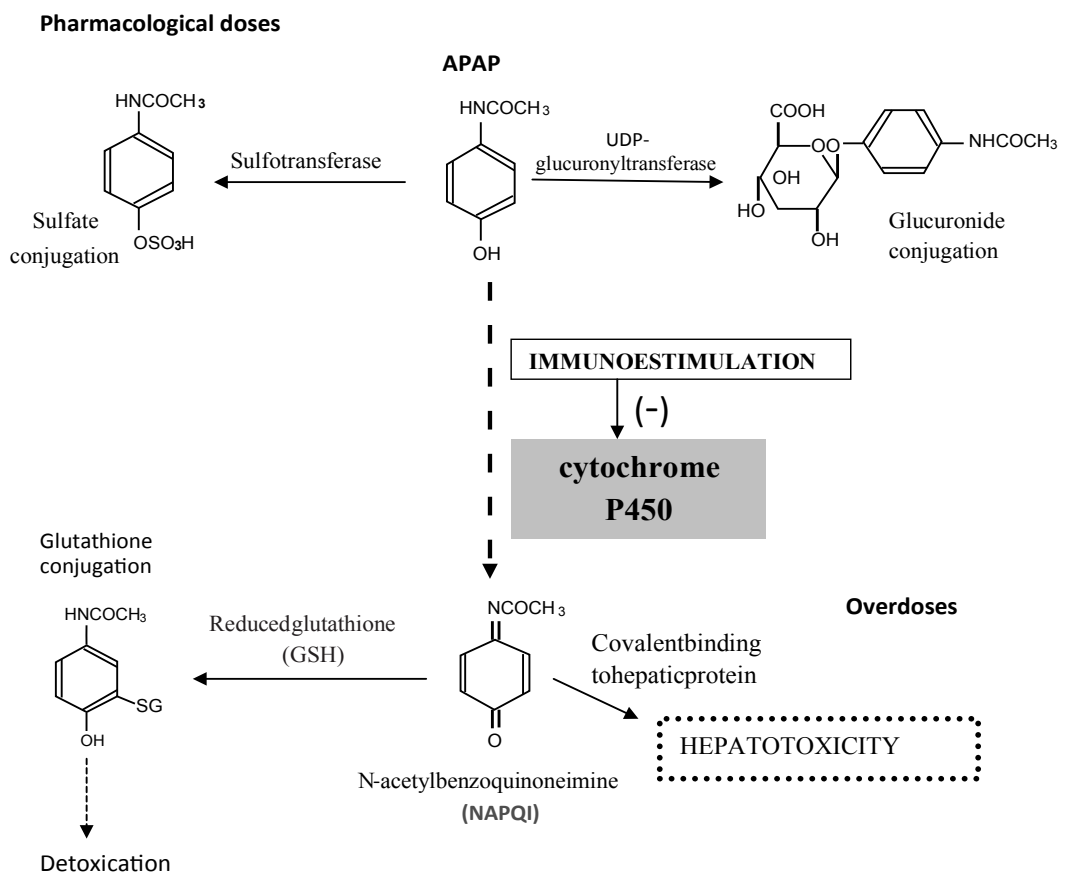

Figure 1: Simplified scheme of the metabolic pathways of APAP

Acetaminophen (APAP) is biotransformed and eliminated as nontoxic sulfate and glucuronic acid conjugates. Cytochrome P450 (CYP) participates in metabolizing a small proportion of APAP at therapeutic doses. The metabolism of APAP by CYP leads to the formation of N-acetylpbenzoquinoneimine (NAPQI), a highly reactive intermediate metabolite, which is normally detoxified by conjugation with reduced glutathione (GSH). After high doses of APAP, the capacity for its removal by hepatic conjugation with glucuronide and sulfate is exceeded, and more of the reactive metabolite NAPQI is formed. Consequently, more NAPQI is conjugated with GSH, and when hepatic GSH is depleted, more NAPQI will bind covalently to cellular macromolecules; this lead to a loss of protein thiol-groups and ultimately to cell necrosis (hepatotoxicity)

levels (CYP2B, CYP2C11, CYP3A1, and CYP2E1), protein contents (CYP2B, CYP2C11, and CYP2E1) or catalytic activities (CYP2C6, CYP2C11, and CYP2E1) [16]. In animal models, using endotoxins as an immuno-stimulation model, also diminished the catalytic activity of CYP2E1 [17,18], including decreased expression of CYP1A, 2B1/2, and $3 \mathrm{~A}$ subfamily associated with reversible changes in the pharmacokinetic parameters of theophylline [18]. In 1994, Raiford and Thigpen reported that Kupffer cells stimulated with Corynebacterium parvum reduced some CYP dependent activities and it was protective against the hepatotoxicity induced by an APAP overdose in rat [19]. After that, Projean reported a rapid decrease in total CYP contents, within $24 \mathrm{~h}$, in the liver of FCA-treated rat and the selective down-regulation of specific CYP isoforms including CYP2E1, accompanied by significant increment of the levels of IL-6 as biomarkers of inflammation [16]. In another study it was showed that both FCA and FIA, elicited a hepatic acute phase response and induction in this organ of TLR2 expression in mice [20]. More recently Kusunoki demonstrated that early hepatic inflammation induces down-regulation of hepatic CYP expression, including CYP2E1, in the dextran sulfate sodium-induced murine colitis [21]. Also it was demonstrated higher plasma concentrations and greater area under the curve associated with manifestations of toxicity of theophylline, in rats treated with FCA that developed inflammatory reactions in the site of injection [22].

Considering that APAP hepatotoxicity is mediated mainly by CYP2E1 biotransformation, that the inflammation decreases the expression or activity of these enzyme families and taking into account the wide use of APAP as an analgesic/antipyretic during inflammatory process, the aim of the present study is to assess the effect of the inflammation in the hepatotoxicity patterns in APAP mild overdoses.

\section{Materials and Methods}

\section{Adjuvants}

Freund Complete Adjuvant (263810) (FCA); is a suspension of Mycobacterium butyricum in a mixture of paraffin oil and an emulsifying agent, mannide monooleate. Formulation per $10 \mathrm{~mL}$ ampule: Mannide Monooleate $(1.5 \mathrm{~mL})$, Paraffin oil $(8.5 \mathrm{~mL})$ and Mycobacterium butyricum (5 mg). Freund Incomplete Adjuvant (263910) (FIA): is essentially FCA without Mycobacteria. Formulation per $10 \mathrm{~mL}$ ampule: Mannide Monooleate $(1.5 \mathrm{~mL})$ and Paraffin oil (8.5 mL). DIFCO Laboratories, Detroit, MI). They were prepared immediately before inoculation according to a well-established method. Briefly adjuvant and a solution of $\mathrm{NaCl} 0.9 \%$ (QUIMEFA, Cuba) were mixed in proportion v/v using two glass syringes with Luer Lock connector during 10 minutes.

\section{Acetaminophen}

APAP purchased from QUIMEFA, Cuba, was prepared as oral suspension at a final concentration of $50 \mathrm{mg} / \mathrm{mL}$ in sterile distilled water.

\section{Animals and treatment}

Female Balb/c mice (20-25 g) were obtained from the National Center for the Laboratory Animals Production (CENPALAB, Havana, Cuba). The present study was conducted according to the Guiding Principles for the Care and Use of Laboratory Animals. The protocol was approved by the Committee on the Ethics of Animal Experiments of Toxicology and Biomedicine Center. All efforts were made to minimize suffering. The animals were maintained under controlled conditions 
Citation: García NP, Lores OF, Fuentes DP, Martínez DT, Hernandez JB, et al. (2014) Reduction of Hepatotoxicity Induced by Acetaminophen Overdoses in a Mouse Model of Inflammation Induced by Freund's Adjuvants. J Allergy Ther 5: 183. doi:10.4172/2155-6121.1000183

Page 3 of 7

\begin{tabular}{|c|c|c|c|c|}
\hline Groups of mice & Product & Dose & Via & Day \\
\hline Control s.c & $\mathrm{NaCl} 0.9 \%$ solution & $100 \mu \mathrm{l}$ & sc & 0,14 \\
\hline Control i.m & $\mathrm{NaCl} 0.9 \%$ solution & $100 \mu \mathrm{l}$ & i.m & 0,14 \\
\hline APAP & APAP suspension & $360 \mathrm{mg} / \mathrm{kg}$ & v.o & $14,15,16$ \\
\hline \multirow[t]{2}{*}{ FA s.c } & FCA emulsion & $100 \mu \mathrm{l}$ & S.c & 0 \\
\hline & FIA emulsion & $100 \mu \mathrm{l}$ & S.c & 14 \\
\hline \multirow[t]{2}{*}{ FA i.m } & FCA emulsion & $100 \mu \mathrm{l}$ & i.m & 0 \\
\hline & FIA emulsion & $100 \mu \mathrm{l}$ & i.m & 14 \\
\hline \multirow[t]{3}{*}{ APAP/FA s.c } & FCA emulsion & $100 \mu \mathrm{l}$ & sc & 0 \\
\hline & FIA emulsion & $100 \mu \mathrm{l}$ & sc & 14 \\
\hline & APAP suspension & $360 \mathrm{mg} / \mathrm{kg}$ & V.o & $14,15,16$ \\
\hline \multirow[t]{3}{*}{ APAP/FA i.m } & FCA emulsion & $100 \mu \mathrm{l}$ & i.m & 0 \\
\hline & FIA emulsion & $100 \mu \mathrm{l}$ & i.m & 14 \\
\hline & APAP suspension & $360 \mathrm{mg} / \mathrm{kg}$ & V.o & $14,15,16$ \\
\hline
\end{tabular}

Table 1: Protocol of treatment in Balb/C mice.

$\left(22^{\circ} \mathrm{C}, 55 \%\right.$ humidity, and 12 -hour day/night rhythm) and fed ratonine (purchased from CENPALAB) and acidulate water at libitum. Five mice by groups were treated according to the protocol shown in Table 1. All mice were clinically observed during the experiment.

\section{Measurement of cytokines in serum}

Cytokine concentrations were determined $8 \mathrm{~h}$ after the second application of Freund's Adjuvant (FA) (14 $4^{\text {th }}$ day) to all groups of mice, using commercially available ELISA kits (eBioscience, San Diego, CA, USA). Briefly, each well of a 96-well plate was coated with $100 \mu \mathrm{L}$ of capture antibody, and incubated overnight at $4^{\circ} \mathrm{C}$. After washing and blocking with assay dilution, serum or standard were added to individual wells; then the plates were maintained for $2 \mathrm{~h}$ at room temperature. The plates were washed while biotin-conjugated detecting mouse antibody was added to each well and incubated at room temperature for $1 \mathrm{~h}$. The plates were washed again and further incubated with avidin-HRP for 30 min before detection with TMB solution. Finally, reactions were stopped by adding $1 \mathrm{M} \mathrm{H}_{3} \mathrm{PO}_{4}$, and the absorbance at $450 \mathrm{~nm}$ was measured with an ELISA reader (Molecular Devices, Sunnyvale, CA, USA). The amount of cytokine was calculated from the linear portion of the generated standard curve.

\section{Biochemical analysis of serum}

The mice were anaesthetized with Pentobarbital $50 \mathrm{mg} / \mathrm{kg}$ IP diluted in a solution of $\mathrm{NaCl} 0.9 \%$ (Quimefa, Cuba) and blood (1,5 $\mathrm{ml}$ ) was drawn from the vein of the tail $24 \mathrm{~h}$ after the last application of APAP (the $17^{\text {th }}$ day). The serum were obtained by coagulation and centrifugation within $15 \mathrm{~min}$ were allowed to clot at room temperature and stored frozen at $-20^{\circ} \mathrm{C}$ until analysis. The aspartic acid aminotransferase (AST), alanine aminotransferase (ALT), and lactate dehydrogenase (LDH) were quantified using a standard clinical automatic analyzer (Hitachi, 902) and specifics kit (Roche). The severity of the inflammatory reaction was assessed by measuring serum concentrations of $\alpha$-1-acid glycoprotein ( $\alpha$-1-AGP) using a commercially available single radial immuno-diffusion method (Cardiotech Services, Inc., Louisville, KY, USA).

\section{Isolation of hepatic microsomal fractions}

Hepatic microsomal fractions of mice were prepared by differential centrifugation, washed in pyrophosphate buffer ( $\mathrm{pH} 7.4)$ and stored in $100 \mathrm{mM}$ Tris-acetate buffer ( $\mathrm{pH} 7.4$ ) containing $1 \mathrm{mM}$ sodium ethylenediamine tetraacetate (EDTA). Microsomal preparations were stored in a $-70^{\circ} \mathrm{C}$ freezer until use.

\section{Immunoblot analysis}

Hepatic microsomes were analyzed for CYP2E1 immunochemically. Microsomal proteins were separated by SDSpolyacrylamide gel electrophoresis ( $10 \%$ acrylamide) at $160 \mathrm{~V}$ for $1 \mathrm{~h}$ and electrophoretically transferred to nitrocellulose paper. The nitrocellulose paper was incubated with anti-mouse cytochrome P-450 CYP2E1 antibodies, with goat antibody to mouse CYP2E1, then with rabbit anti-goat IgG conjugated with alkaline phophatase (Bio-Rad). The color was developed with 5-bromo- 4-chloro-3-indole toluidine phosphate and p-nitroblue tetrazolium chloride (Bio-Rad) according to the manufacturer's instructions. The resulting blots were quantitated by densitometry, using Adobe Photoshop with a HP Precision Scanner and OneDScan software (Scanalytics) [23].

\section{Necropsy and histopathology}

After the blood collection, anaesthetized animals were sacrificed by cervical dislocation. Necropsy was made and all organs were macroscopically examined. Them, histological processing was performed according to standardized methods. Briefly, the sites of inoculation (dorsal subcutaneous tissue for subcutaneous or anterior quadriceps muscle groups of the left hindpaw for intramuscular) and the livers obtained from all treated mice, were fixed in $10 \%$ formalin, embedded in paraffin, sectioned at $4 \mu \mathrm{m}$ thickness and stained with hematoxylin and eosin.

\section{Statistical analysis}

All data are reported as means \pm S.D. The comparison of the results from the various experimental groups and their corresponding controls was carried out using a one-way analysis of variance followed by Turkey's post hoc test. The effects were considered significant when $p \leq 0.05$. The statistical analyses were performed using Statgraphics plus 5.1 software (StatSoft).

\section{Results}

\section{Measurement of cytokines and biochemical analysis in serum}

After 8 hours of applying the second dose of Freund's Adjuvants (FA), the concentration of pro-inflamatory cytokine IL-1 $\beta$, TNFa and IFN $\gamma$ were observed to increase in the serum of all the groups of mice that received Freund's Adjuvants (FA) (Figure 2).

Analyzing the enzymatic level in the treated groups, it was noted that a significant increment of ALT and AST in the APAP-treated group as evidence of hepatotoxicity induced by the overdose. However, it is interesting that in the group with co-administration of FA the levels of both enzymes were lower than positive control treated with APAP alone, indicating a hepatoprotective effect provoked by the inflammation (Figure 3).

Regarding to a-1-AGP levels, it was significantly increased in all mice treated with FA without affection for the APAP treatment (Figure 4). LDH were significantly increased in the serum of mice treated with APAP, FA and combined treatment in comparison with control groups. However, there were differences within these treated groups. Mice treated with APAP and previous s.c application of FA exhibited higher level of LDH than the other groups, being significant difference in comparison with APAP and APAP/FA i.m groups (Figure 5).

\section{Expression of CYP2E1 in the liver}

CYP2E1 was identified as a single band that appeared at approximately $56 \mathrm{kDa}$. In the groups treated with $\mathrm{FA}$, the expression 
Citation: García NP, Lores OF, Fuentes DP, Martínez DT, Hernandez JB, et al. (2014) Reduction of Hepatotoxicity Induced by Acetaminophen Overdoses in a Mouse Model of Inflammation Induced by Freund's Adjuvants. J Allergy Ther 5: 183. doi:10.4172/2155-6121.1000183

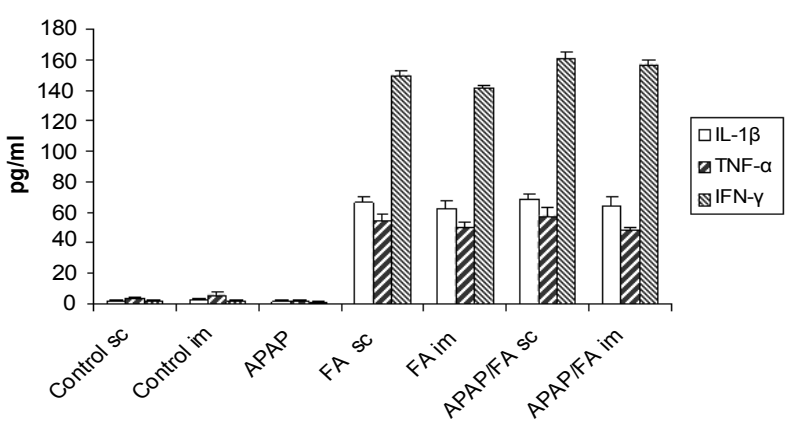

Figure 2: Effect of administration of Freund's Adjuvants (FA) via either i.m or s.c routes in the levels of IL-1 $\beta$, TNFa and IFNy in serum of mice Balb/c. The serum levels of IL-1 $\beta$, TNF $\alpha$ and IFNy were measured in all treated groups and controls. Mice $(n=5)$ were bled at $14^{\text {th }}, 8 \mathrm{~h}$ after application of FA and before administration of APAP. Serum was pooled from each group and measured serum cytokine profile in triplicates by ELISA.

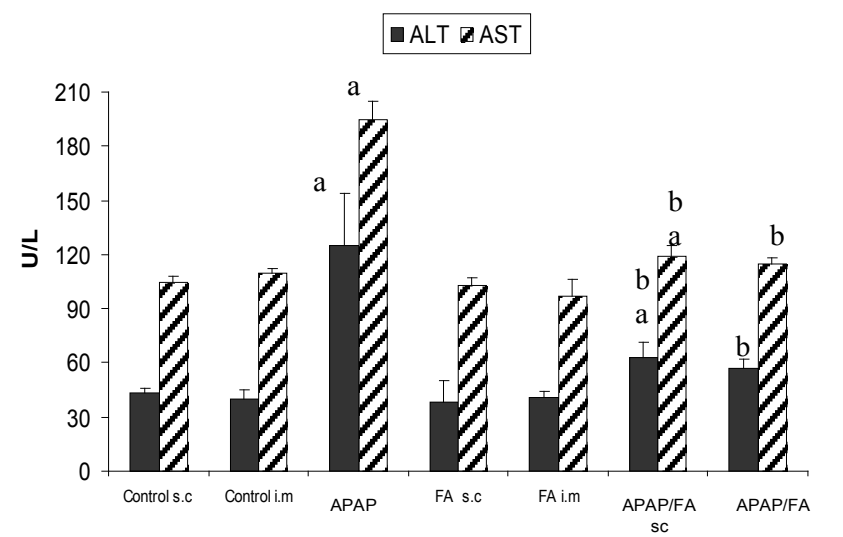

Figure 3: Effect of administration of Freund's adjuvants (FA) via either i.m or s.c routes in the levels of ALT and AST in serum in a mice model of APAP hepatotoxicity. All values are expressed as the arithmetic mean \pm SE of 5 mice. a: significative difference in comparison with control groups, b: significative difference in comparison with APAP group $(p<0.05)$. Only are marked the more important differences $(p<0.05)$. (ANOVA followed by Turkey's post hoc test).

of CYP2E1 was significantly decreased to approximately $40-50 \%$ in comparison with the control groups. Apparently the groups that received FA via s.c route had lower expression in comparison with the groups treated via i.m route, but this difference was not statistically significant (Figure 6).

\section{Pathological findings in the injection site and the liver}

The main pathological finding at the injection sites and the liver in all the mice groups are detailed in Table 2 . Mice previously immunostimulated with FA (i.m and s.c), showed inflammatory reactions in the injection site. The group under APAP treatment exhibited signs of mild hepatic necrosis, and other changes in the hepatic morphology according to the pattern produced by moderate overdoses of APAP, while mice with both treatment APAP and FA developed slight changes indicating a hepatoprotection, and not relevant modification on the tissue architecture in the other groups (Figure 7).

\section{Discussion}

APAP is frequently prescribed in the medical practice as analgesic

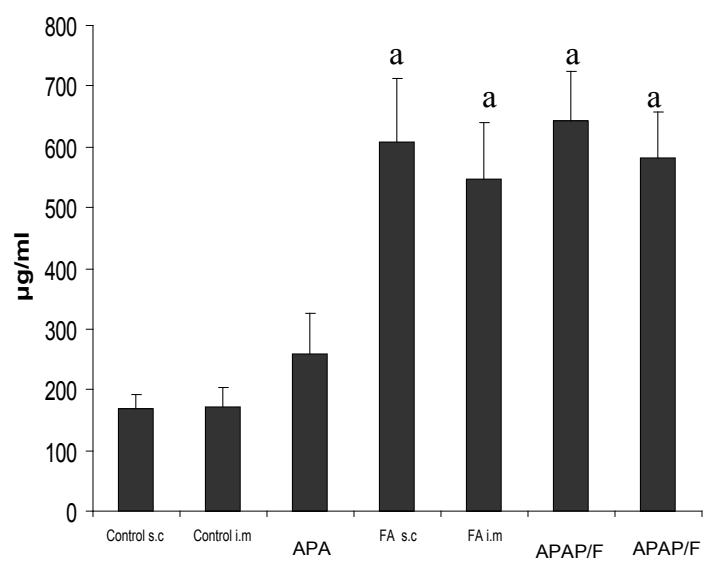

Figure 4: Effect of administration of Freunds's Adjuvants (FA) via either i.m or s.c routes in the levels of $\alpha-1$-acid glycoprotein ( $\alpha-1-A G P)$ in serum in a mice model of Acetaminophen (APAP) hepatotoxicity All values are expressed as the arithmetic mean \pm SE of 5 mice. In FA-treated mice, $\alpha$-1-AGP levels were significantly increased (a) when compared with their correspondent control group and APAP treated group, $(p<0.05)$ (ANOVA followed by Tukey's post hoc test).

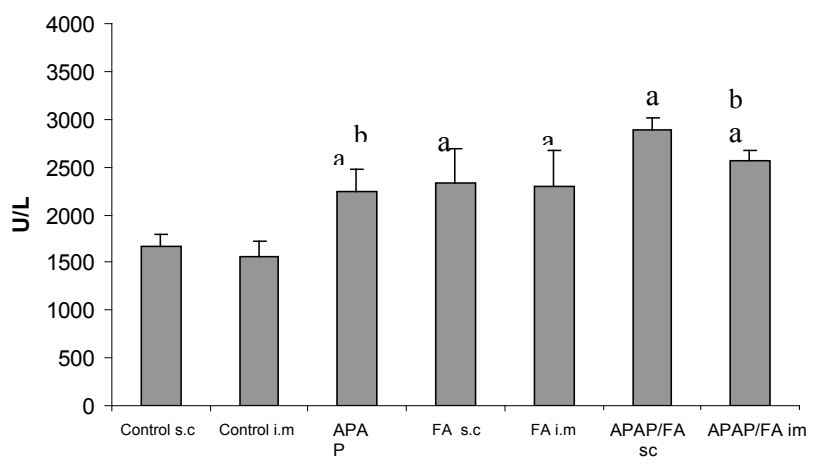

Figure 5: Effect of administration of Freund's adjuvants (FA) via either i.m or s.c routes in the levels of lactate dehydrogenase (LDH) in serum in a mice model of Acetaminophen (APAP) hepatotoxicity hepatotoxicity. All values are expressed as the arithmetic mean \pm SE of 5 mice. (a): significative difference in comparison with control groups, (b): significative difference in comparison with APAP/FA group, $(p<0.05)$. (ANOVA followed by Turkey's post hoc test.

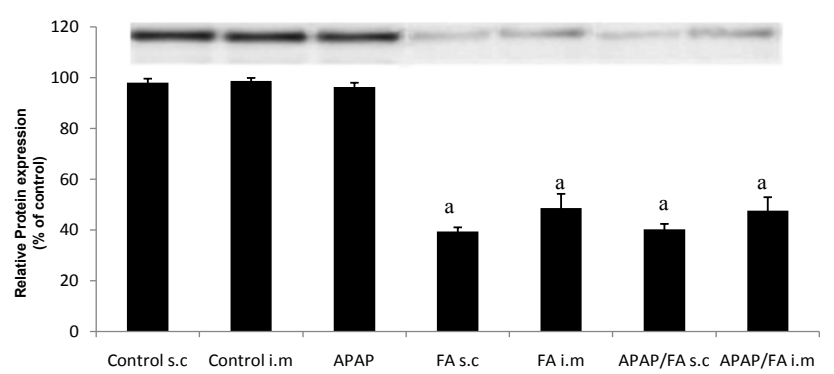

Figure 6: Hepatic cytochrome P-450 (CYP2E1) expression in negative contro subcutaneous (s.c) and intramuscular (i.m), positive control of Acetaminophen (APAP) hepatotoxicity, Freund's adjuvants (FA) administrated s.c or i.m and combination of APAP/FA s.C or APAP/FA i.m mice groups, quantitated by immuno-blotting and densitometry. The averages of the values derived from the control mice were expressed as $100 \%$. The data are presented as the means \pm S.D. and were obtained from five mice per group.

(a) represents significative difference when compared with their correspondent control group and APAP treated group, $(p<0.05)$ (ANOVA followed by Turkey's post hoc test). 
Citation: García NP, Lores OF, Fuentes DP, Martínez DT, Hernandez JB, et al. (2014) Reduction of Hepatotoxicity Induced by Acetaminophen Overdoses in a Mouse Model of Inflammation Induced by Freund's Adjuvants. J Allergy Ther 5: 183. doi:10.4172/2155-6121.1000183

Page 5 of 7

\begin{tabular}{|c|c|c|c|c|}
\hline \multirow[t]{2}{*}{ Groups } & \multicolumn{2}{|c|}{ Macroscopic findings } & \multicolumn{2}{|c|}{ Microscopic findings } \\
\hline & Inoculation site & Liver & Inoculation site & Liver \\
\hline Control s.c & $\begin{array}{l}\text { Absence of visible tisular } \\
\text { alterations }\end{array}$ & $\begin{array}{l}\text { Absence of visible tisular } \\
\text { alterations }\end{array}$ & $\begin{array}{l}\text { Absence of inflammatory infiltrate or } \\
\text { others microscopic alterations }\end{array}$ & Absence of alterations in the hepatic tissue \\
\hline Control i.m & $\begin{array}{l}\text { Absence of visible tisular } \\
\text { alterations }\end{array}$ & $\begin{array}{l}\text { Absence of visible tisular } \\
\text { alterations }\end{array}$ & $\begin{array}{l}\text { Absence of inflammatory infiltrate or } \\
\text { others microscopic alterations }\end{array}$ & Absence of alterations in the hepatic tissue \\
\hline Acetam & - & $\begin{array}{l}\text { Moderate irregular liver's } \\
\text { yellowish coloration }\end{array}$ & - & $\begin{array}{l}\text { Focus of necrosis parenchymal, degenerated } \\
\text { parenchymal hepatocytes multizonal, vascular } \\
\text { congestion and swelling of hepatocytes }\end{array}$ \\
\hline FA s.c & $\begin{array}{l}\text { Nodule }>5 \mathrm{~mm} \text {, large amount of } \\
\text { white tissue and haemorrhagic } \\
\text { zones }\end{array}$ & $\begin{array}{l}\text { Absence of visible tisular } \\
\text { alterations }\end{array}$ & $\begin{array}{l}\text { Severe diffuse inflammation, } \\
\text { necrotising granuloma }\end{array}$ & Absence of alterations in the hepatic tissue \\
\hline FA i.m & $\begin{array}{l}\text { Localized nodular Inflammatory } \\
\text { zone }\end{array}$ & $\begin{array}{l}\text { Absence of visible tisular } \\
\text { alterations }\end{array}$ & $\begin{array}{l}\text { Inflammation with necrotising } \\
\text { granuloma }\end{array}$ & Absence of alterations in the hepatic tissue \\
\hline $\begin{array}{l}\text { Acetam/ FA } \\
\text { S.c }\end{array}$ & $\begin{array}{l}\text { Nodule }>5 \mathrm{~mm} \text {, large amount of } \\
\text { white tissue and haemorrhagic } \\
\text { zones }\end{array}$ & Light liver's yellowish coloration & $\begin{array}{l}\text { Severe diffuse inflammation } \\
\text { necrotising granuloma }\end{array}$ & $\begin{array}{l}\text { Light degenerated parenchymal hepatocytes, } \\
\text { with very scarce and little necrosis focus }\end{array}$ \\
\hline $\begin{array}{l}\text { Acetam/ FA } \\
\text { S.c }\end{array}$ & $\begin{array}{l}\text { Localized nodular Inflammatory } \\
\text { zone }\end{array}$ & Light liver's yellowish coloration & $\begin{array}{l}\text { Inflammation with necrotising } \\
\text { granuloma }\end{array}$ & $\begin{array}{l}\text { Light degenerated parenchymal hepatocytes, } \\
\text { with scarce necrosis focus }\end{array}$ \\
\hline
\end{tabular}

Table 2: Main pathological finding at injection sites and liver of treated mice groups $(n=5)$.

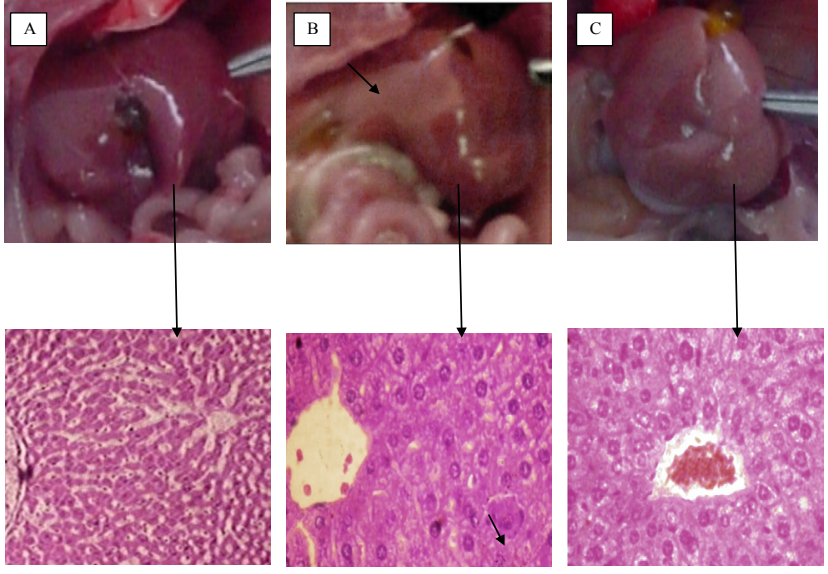

Figure 7: Selected histological images of the livers after oral administration of Acetaminophen (APAP) in normal or treated mice with Freund's Adjuvants (FA). Representative images of macroscopic (upper panels) and microscopic (lower panel) pathological findings. (A) Vehicle control group $(\times 100),(B)$ APAP treated group, (arrow indicates a focus of hepatic necrosis) $(\times 400),(\mathrm{C})$ APAP plus FA treatment group $(\times 400)$. Livers from mice treated with FA without APAP did not show any damage (not shown).

and antipyretic during inflammatory process. On the other hand, overdose of APAP is the most frequent cause of drug induced hepatic failure in several countries [24]. Several studies have revealed that inflammation and immuno-stimulation can modulate the expression of different CYP enzymes, affecting the metabolism of some drugs [1-4]. In this way, Prandota has reviewed a lot of cytokines, growth factors and other substances released during inflammatory response with down-regulating effects on the metabolism of endogenous and exogenous substances [25].

This study has highlighted the role of inflammation induced by FA on the modulation of hepatotoxicity after APAP overdose, incriminating the role of proinflammatory cytokines on the inhibition of the CYP activity, reducing the APAP-induced hepatotoxicity. The dose used was $360 \mathrm{mg} / \mathrm{kg}$ via oral route, which induced an increment of biomarkers of hepatic damages and provoked a moderated hepatotoxicity that is able to detect an effect of the inflammation induced by FA in the mice model. The releasing of cytokines, such as IL-1, IL-2, IL-6, TNF $\alpha$, TGF- $\beta$ and
IFNs during immuno-stimulation are involved in the reduction of the expression of CYP2E1 [26] and the modulation of drug metabolism, as was evidence by Masubuchi et al., who demonstrated the role of IL-6 in hepatic heat shock protein expression and protection against acetaminophen-induced liver disease, using IL-6-knockout mice [27]. In this study was measured the concentration of the pro-inflammatory cytokines: IL- $1 \beta, T N F a$ and IFN $\gamma$ in sera in mice $8 \mathrm{~h}$ after the second application of FA, and before application of APAP, and it was observed their elevation as expression of the inflammatory reaction occurring in the inoculation site of the adjuvants.

AGP is other biomarker of acute inflammation elevated in the groups that received FA. AGP is an acute phase protein, which binds basic drugs, and has been proposed to have a role in immunomodulation and to be a nonspecific antimicrobial agent $[28,29]$. In rats treated with a single dose of FCA, the inflammatory response observed 14 days post-injection (FCA-induced arthritis) is characterized by pathophysiological changes that can alter drug disposition, namely elevated serum levels of AGP [30]. Considering that AGP is able to binds to drugs, further studies of its influence in pharmacokinetic and pharmacodynamic properties of APAP in this model needs to be studied in the future.

The hepatic enzymes ALT and AST are the best enzymatic marker of hepatic necrosis, in particular ALT is the clinical chemistry gold standard of hepatotoxicity. Damaged hepatocytes release their contents including ALT and AST into the extracellular space. The released enzymes ultimately enter into circulation and thereby increase the serum levels of ALT and AST compared to control subjects [31]. In this study, the group treated with APAP showed significant increment of these enzymes in sera due to the hepatic damaged induced by this drug, but in the groups injected with FA and APAP there was not observed such increment, as evidence of protection against APAP-induced hepatotoxicity in animal receiving FA. Regarding to $\mathrm{LDH}$, despite being less specific, it has been used as a marker to evaluate the damage to hepatic tissue membranes by APAP [32]. In all the groups that received APAP and FA plus APAP, the $\mathrm{LDH}$ were elevated in contrast with the control groups. Taking into count that $\mathrm{LDH}$ is a unspecific biomarker of cellular necrosis, is possible that this result is produced by the sum of the effects of the cellular necrosis at the inoculation site induced by FA in addition to that occurred in the liver by the APAPinduced hepatotoxicity. 
Citation: García NP, Lores OF, Fuentes DP, Martínez DT, Hernandez JB, et al. (2014) Reduction of Hepatotoxicity Induced by Acetaminophen Overdoses in a Mouse Model of Inflammation Induced by Freund's Adjuvants. J Allergy Ther 5: 183. doi:10.4172/2155-6121.1000183

Page 6 of 7

Many investigators reported that CYP2E1 is the main CYP isoform involved in APAP hepatotoxicity [8-11]. In this study was observed a decreased expression in mice previously treated with FA. This effect may have contributed to reduce the APAP hepatotoxicity. Similar result was reached by other authors using a model of immuno-stimulation with C. parvum [19]. The protective effect induced by the inflammatory response was directly evidenced in the pathological studies of the livers of the group treated with APAP plus FA with a reduction of the hepatic necrosis.

Although our study reveals one aspect of the inflammatory response and its influence in reducing hepatotoxicity by paracetamol, this phenomenon is very complex and other factors not evaluated in our study can also be involved. For example, Kupffer cells can be activated directly or indirectly by various toxicants, including paracetamol, or by the hepatocyte damage initiated by the formation of the reactive metabolite, $N$-acetyl-p-benzoquinoneimine, resulting in the release of reactive oxygen and nitrogen species, all of which may contribute to liver damage with implications in the toxicity [12-15,33]. Thus was reported that the antioxidant effect of beta-D-glucan can prevent the APAP-induced toxicity [34].

Other important issue which reveals the complexity of this effect is that, hepatocyte death results in a sterile inflammatory response and activation of molecular pathways for innate immune activation, such as TLR 9 and the Nalp3 inflammasome, producing proinflammatory cytokines that amplifies the initial insult and increases overall tissue injury, as was demonstrated in mice deficient in Tlr9 and the inflammasome components Nalp3 (NACHT, LRR, and pyrin domain-containing protein 3) [35], and using neutralizing antibodies to TNFa or IL-1 partially prevented liver damage in mice initiated by hepatotoxic doses of APAP [36]. For this reason we measured the level of pro-inflammatory cytokines before the administration of APAP. Besides, some immuno-stimulators such as lipopolysaccharide (LPS) from Gram-negative bacteria can itself induce liver damage, and act in synergy with APAP for the production of pro-inflammatory cytokines [37]. In contrast, in the model of carbon tetrachloride $\left(\mathrm{CCl}_{4}\right)$ exposure in mice, TNFa was involved in liver repair through its ability to support hepatocyte proliferation following chemical injury [38]. In spite of the diversity of factors that participate in the APAP hepatotoxicity, our results confirm the role of the previous immuno-stimulation, reducing the hepatotoxic effect of this drug.

In conclusion, this result suggest that the use of APAP for the treatment of pain or fever as part of the flu-like syndrome induced by vaccines or immuno-modulators [39-41], and during inflammatory process, does not increase the risk of toxicity in overdose, quite the contrary, this risk probably is reduced. Further studies are required measuring glutathione (GSH), other cytokines involved in the inflammatory process and other members of the CYP in this and other models of inflammation.

\section{References}

1. Renton KW (2000) Hepatic drug metabolism and immunostimulation. Toxicology 142: 173-178.

2. Descotes J (1985) Immunomodulating agents and hepatic drug-metabolizing enzymes. Drug Metab Rev 16: 175-184.

3. Shedlofsky SI, Israel BC, McClain CJ, Hill DB, Blouin RA (1994) Endotoxin administration to humans inhibits hepatic cytochrome P450-mediated drug metabolism. J Clin Invest 94: 2209-2214.

4. Robertson WC Jr (2002) Carbamazepine toxicity after influenza vaccination Pediatr Neurol 26: 61-63.
5. Davidson DG, Eastham WN (1966) Acute liver necrosis following overdose of paracetamol. Br Med J 2: 497-499.

6. Sumioka I, Mansura T, Yamada K (2004) Acetaminophen-induced hepatotoxicity: still an important issue. Yonago Acta Medica 47: 17-28

7. Hazai E, Vereczkey L, Monostory K (2002) Reduction of toxic metabolite formation of acetaminophen. Biochem Biophys Res Commun 291: 1089-1094.

8. Lee SS, Buters JT, Pineau T, Fernandez-Salguero P, Gonzalez FJ (1996) Role of CYP2E1 in the hepatotoxicity of acetaminophen. J Biol Chem 271: 1206312067.

9. Manyike PT, Kharasch ED, Kalhorn TF, Slattery JT (2000) Contribution of CYP2E1 and CYP3A to acetaminophen reactive metabolite formation. Clin Pharmacol Ther 67: 275-282.

10. Cheung C, Yu AM, Ward JM, Krausz KW, Akiyama TE, et al. (2005) The cyp2e1-humanized transgenic mouse: role of cyp2e1 in acetaminophen hepatotoxicity. Drug Metab Dispos 33: 449-457.

11. Gonzalez FJ (2007) The 2006 Bernard B. Brodie Award Lecture. Cyp2e1. Drug Metab Dispos 35: 1-8.

12. Knight TR, Kurtz A, Bajt ML, Hinson JA, Jaeschke H (2001) Vascular and hepatocellular peroxynitrite formation during acetaminophen-induced liver injury: role of mitochondrial oxidant stress. Toxicol Sci 62: 212-220

13. Chen LH, Lin SM (1997) Modulation of acetaminophen-induced alterations of antioxidant defense enzymes by antioxidants or glutathione precursors in cultured hepatocytes. Biochem Arch 13: 113-125

14. Lores Arnaiz S, Llesuy S, Cutrín JC, Boveris A (1995) Oxidative stress by acute acetaminophen administration in mouse liver. Free Radic Biol Med 19: 303-310.

15. Hinson JA, Roberts DW, James LP (2010) Mechanisms of acetaminopheninduced liver necrosis. Handb Exp Pharmacol : 369-405.

16. Projean D, Dautrey S, Vu HK, Groblewski T, Brazier JL, et al. (2005) Selective downregulation of hepatic cytochrome $\mathrm{P} 450$ expression and activity in a rat model of inflammatory pain. Pharm Res 22: 62-70.

17. Abdulla D, Goralski KB, Renton KW (2006) The regulation of cytochrome P450 2E1 during LPS-induced inflammation in the rat. Toxicol Appl Pharmacol 216 $1-10$.

18. Yang KH, Jung YS, Lee DY, Lee JH, Kim YC, et al. (2008) Time-dependent effects of Klebsiella pneumoniae endotoxin (KPLPS) on the pharmacokinetics of theophylline in rats: return of the parameters in 96-hour KPLPS rats to the control levels. Drug Metab Dispos 36: 811-815.

19. Raiford DS, Thigpen MC (1994) Kupffer cell stimulation with Corynebacterium parvum reduces some cytochrome P450-dependent activities and diminishes acetaminophen and carbon tetrachloride-induced liver injury in the rat. Toxico Appl Pharmacol 129: 36-45

20. Lim SK (2003) Freund adjuvant induces TLR2 but not TLR4 expression in the liver of mice. Int Immunopharmacol 3: 115-118.

21. Kusunoki Y, Ikarashi N, Hayakawa Y, Ishii M, Kon R, et al. (2014) Hepatic early inflammation induces down regulation of hepatic cytochrome P450 expression and metabolicactivity inthe dextran sulfate sodium induced murine colitis. Eur J Pharm Sci 54:17-27

22. Batista-Duharte A, Fong OL, Rodríguez JCT, Puente EZ, Pérez O (2012) Effect of intranasal vaccine adjuvant AFCo1 on plasma concentration of theophylline in rats. MEDISAN 16: 1284-1294

23. Wolf KK, Wood SG, Allard JL, Hunt JA, Gorman N (2007) Role of CYP3A and CYP2E1 in Alcohol-Mediated Increases in Acetaminophen Hepatotoxicity: Comparison of Wild-Type and Cyp2e1 ( / ) Mice. Drug Metabolism Disposition 35: $1223-1231$

24. Lee WM (2004) Acetaminophen and the U.S. Acute Liver Failure Study Group lowering the risks of hepatic failure. Hepatology 40: 6-9.

25. Prandota J (2005) Important role of proinflammatory cytokines/othe endogenous substances in drug-induced hepatotoxicity: depression of drug metabolism during infections/inflammation states, and genetic polymorphisms of drug-metabolizing enzymes/cytokines may markedly contribute to this pathology. Am J Ther 12: 254-261

26. Hakkola J, Hu Y, Ingelman-Sundberg M (2003) Mechanisms of down-regulation of CYP2E1 expression by inflammatory cytokines in rat hepatoma cells. J Pharmacol Exp Ther 304: 1048-1054. 
Citation: García NP, Lores OF, Fuentes DP, Martínez DT, Hernandez JB, et al. (2014) Reduction of Hepatotoxicity Induced by Acetaminophen Overdoses in a Mouse Model of Inflammation Induced by Freund's Adjuvants. J Allergy Ther 5: 183. doi:10.4172/2155-6121.1000183

Page 7 of 7

27. Masubuchi Y, Bourdi M, Reilly TP, Graf ML, George JW, et al. (2003) Role of interleukin- 6 in hepatic heat shock protein expression and protection against acetaminophen-induced liver disease. Biochem Biophys Res Commun 304: 207-212.

28. Hagman R (2011) Serum Ît-1-acid glycoprotein concentrations in 26 dogs with pyometra. Vet Clin Pathol 40: 52-59.

29. Crestani B, Rolland C, Lardeux B, Fournier T, Bernuau D, et al. (1998) Inducible expression of the alpha1-acid glycoprotein by rat and human type II alveolar epithelial cells. J Immunol 160: 4596-4605.

30. Projean D, Lessard E, Ducharme MP, Ducharme J (2007) Use of Freund's Complete Adjuvant (FCA) in inflammatory pain models: consequences on the metabolism and pharmacokinetics of the non-peptidic delta receptor agonist SNC80 in the rat. Xenobiotica 37: 870-883.

31. Ozer J, Ratner M, Shaw M, Bailey W, Schomaker S (2008) The current state of serum biomarkers of hepatotoxicity. Toxicology 245: 194-205.

32. Das J, Ghosh J, Manna P, Sil PC (2010) Acetaminophen induced acute liver failure via oxidative stress and JNK activation: protective role of taurine by the suppression of cytochrome P450 2E1. Free Radic Res 44: 340-355.

33. Dragomir AC, Laskin JD, Laskin DL (2011) Macrophage activation by factors released from acetaminophen-injured hepatocytes: potential role of HMGB1. Toxicol Appl Pharmacol 253: 170-177.
34. Toklu HZ, Sehirli AO, Velioğlu-Oğünç A, Cetinel S, Sener G. (2006) Acetaminophen-induced toxicity is prevented by beta-D-glucan treatment in mice. Eur J Pharmacol 43: 133-140

35. Imaeda AB, Watanabe A, Sohail MA, Mahmood S, Mohamadnejad M, et al (2009) Acetaminophen-induced hepatotoxicity in mice is dependent on TIr9 and the Nalp3 inflammasome. J Clin Invest 119: 305-314.

36. Blazka ME, Wilmer JL, Holladay SD, Wilson RE, Luster MI (1995) Role of proinflammatory cytokines in acetaminophen hepatotoxicity. Toxicol Appl Pharmacol 133: 43-52.

37. Lacour S, Antonios D, Gautier JC, Pallardy M (2009) Acetaminophen and lipopolysaccharide act in synergy for the production of pro-inflammatory cytokines in murine RAW264.7 macrophages. J Immunotoxicol 6: 84-93.

38. Luster MI, Simeonova PP, Gallucci RM, Bruccoleri A, Blazka ME, et al. (2001) Role of inflammation in chemical-induced hepatotoxicity. Toxicol Lett 120: 317321.

39. Gribble EJ, Sivakumar PV, Ponce RA, Hughes SD (2007) Toxicity as a result of immunostimulation by biologics. Expert Opin Drug Metab Toxicol 3: 209-234.

40. Batista-Duharte A, Lindblad EB, Oviedo-Orta E (2011) Progress in understanding adjuvant immunotoxicity mechanisms. Toxicol Lett 203: 97-105.

41. Batista-Duharte A, Portuondo D, Pérez O, Carlos IZ (2014) Systemic immunotoxicity reactions induced by adjuvanted vaccines. Int Immunopharmaco 20: $170-180$. 